\title{
Characterization of Creatine Kinase Levels in Tofacitinib-Treated Patients with Ulcerative Colitis: Results from Clinical Trials
}

\author{
Remo Panaccione ${ }^{1}$ (D) John D. Isaacs ${ }^{2} \cdot$ Lea Ann Chen ${ }^{3} \cdot$ Wenjin Wang ${ }^{4} \cdot$ Amy Marren $^{4} \cdot K_{\text {Kenneth Kwok }}^{5} \cdot$ Lisy Wang $^{6}$. \\ Gary Chan ${ }^{4}$. Chinyu Su ${ }^{4}$
}

Received: 4 May 2020 / Accepted: 11 August 2020 / Published online: 20 August 2020

(c) The Author(s) 2020, corrected publication 2020

\begin{abstract}
Background Tofacitinib is an oral, small-molecule JAK inhibitor for the treatment of ulcerative colitis (UC). Creatine kinase (CK) levels and CK-related adverse events (AEs) in tofacitinib-treated patients with UC were evaluated.

Methods Data were analyzed for three UC cohorts: Induction (phase 2 and 3 induction studies); Maintenance (phase 3 maintenance study); Overall [patients who received tofacitinib 5 or $10 \mathrm{mg}$ twice daily (b.d.) in phase 2, phase 3, or openlabel, long-term extension studies; data at November 2017]. Clinical trial data for tofacitinib-treated patients with rheumatoid arthritis, psoriasis, and psoriatic arthritis are presented for contextualization.

Results Week 8 mean change from baseline CK with tofacitinib $10 \mathrm{mg}$ b.d. induction therapy was $91.1 \mathrm{U} / \mathrm{L}$ (95\% CI, $48.1-$ 134.1) versus 19.2 U/L (8.5-29.9) with placebo. Among patients completing induction with $10 \mathrm{mg}$ b.d. and re-randomized to 52 weeks of maintenance therapy, mean increases from induction baseline to the end of maintenance were 35.9 (8.1-63.7), 90.3 (51.9-128.7), and 115.6 U/L (91.6-139.7), with placebo, 5 and $10 \mathrm{mg}$ b.d., respectively. The incidence rate (unique patients with events per 100 patient-years) for AEs of CK elevation in the tofacitinib-treated UC Overall cohort was 6.6 versus 2.2, 6.5, and 3.7 for tofacitinib-treated patients with rheumatoid arthritis, psoriasis, and psoriatic arthritis, respectively. No serious AEs of CK elevation or AEs of myopathy occurred in UC studies.

Conclusions In patients with UC, CK elevations with tofacitinib appeared reversible and not associated with clinically significant AEs. UC findings were consistent with tofacitinib use in other inflammatory diseases.

Trial Registration NCT00787202; NCT01465763; NCT01458951; NCT01458574; NCT01470612; NCT01262118; NCT01484561; NCT00147498; NCT00413660; NCT00550446; NCT00603512; NCT00687193; NCT01059864; NCT01164579; NCT00976599; NCT01359150; NCT02147587; NCT00960440; NCT00847613; NCT00814307; NCT00856544; NCT00853385; NCT01039688; NCT02187055; NCT00413699; NCT00661661; NCT01710046; NCT00678210; NCT01276639; NCT01309737; NCT01241591; NCT01186744; NCT01163253; NCT01877668; NCT01882439; NCT01976364.
\end{abstract}

Keywords Ulcerative colitis $\cdot$ Inflammatory bowel disease $\cdot$ Tofacitinib $\cdot$ Creatine kinase $\cdot$ Safety

$\begin{array}{ll}\text { Abbreviations } \\ \text { AE } & \text { Adverse event } \\ \text { b.d. } & \text { Twice daily } \\ \text { BMI } & \text { Body mass index } \\ \text { CI } & \text { Confidence interval } \\ \text { CK } & \text { Creatine kinase }\end{array}$

Electronic supplementary material The online version of this article (https://doi.org/10.1007/s10620-020-06560-4) contains supplementary material, which is available to authorized users.

Remo Panaccione rpanacci@ucalgary.ca

$\begin{array}{ll}\text { CRP } & \text { C-reactive protein } \\ \text { HR } & \text { Hazard ratio } \\ \text { IR } & \text { Incidence rate } \\ \text { JAK } & \text { Janus kinase } \\ \text { MedDRA } & \text { Medical Dictionary for Regulatory Activities } \\ \text { OLE } & \text { Open-label, long-term extension } \\ \text { PsA } & \text { Psoriatic arthritis } \\ \text { Pso } & \text { Psoriasis } \\ \text { PT } & \text { Preferred term } \\ \text { RA } & \text { Rheumatoid arthritis } \\ \text { SD } & \text { Standard deviation } \\ \text { TNFi } & \text { Tumor necrosis factor inhibitor }\end{array}$

Extended author information available on the last page of the article 


\section{UC Ulcerative colitis \\ ULN Upper limit of normal}

\section{Introduction}

Creatine and its associated enzyme creatine kinase (CK) play a central role in energy metabolism through the cellular mediation of adenosine triphosphate demand [1]. The CK-M cytosolic isoform of CK is expressed primarily in skeletal and cardiac muscle, while the CK-B cytosolic isoform is present in non-muscle tissues [1].

Elevations in CK may be indicative of neuromuscular conditions, including myositis, myopathy, and rhabdomyolysis [2, 3]. CK elevations may also occur due to exercise, endocrine disorders, and the use of prescription drugs and supplements [4]. CK levels may be impacted by gender, ethnicity, and age [2, 5-7], and accordingly, defining normal reference ranges for $\mathrm{CK}$ is challenging. A number of studies have demonstrated that manufacture-determined assay reference ranges categorize a substantial proportion of otherwise asymptomatic subjects as having elevated CK levels [8-10].

Tofacitinib is an oral, small-molecule Janus kinase (JAK) inhibitor for the treatment of ulcerative colitis (UC). Elevations in CK have been observed with JAK inhibitors, including tofacitinib [11-13], baricitinib [14], and upadacitinib [15-17], during the treatment of a range of inflammatory diseases. CK elevations with tofacitinib have been shown to be reversible with tofacitinib withdrawal [18] and not associated with myopathies [19]. Asymptomatic, drug-related CK elevations have also been observed with infliximab, a tumor necrosis factor inhibitor (TNFi) used to treat inflammatory bowel disease [20]. However, the origin and implications of CK elevations in patients with UC have not been fully explored.

In this analysis of data from tofacitinib UC clinical studies, we aimed to characterize changes in CK levels, understand the potential clinical significance of these changes, and evaluate possible risk factors. We also present data from tofacitinib-treated patients with rheumatoid arthritis (RA), psoriasis (Pso), and psoriatic arthritis (PsA) to contextualize the data from the UC program.

\section{Methods}

\section{Tofacitinib UC Studies}

Data for patients with UC were obtained from an 8-week, double-blind, placebo-controlled phase 2 induction study (A3921063, NCT00787202) [21]; two identical, 8-week, double-blind, placebo-controlled phase 3 induction studies (OCTAVE Induction 1 and 2, NCT01465763 \& NCT01458951) [12]; a 52-week, double-blind, placebocontrolled phase 3 maintenance study (OCTAVE Sustain, NCT01458574) [12]; and an ongoing, open-label, long-term extension (OLE) study (OCTAVE Open, NCT01470612; data as of November 2017 data cutoff) [22] (Fig. 1). Study design and results from these studies have been previously reported [12, 21, 22].

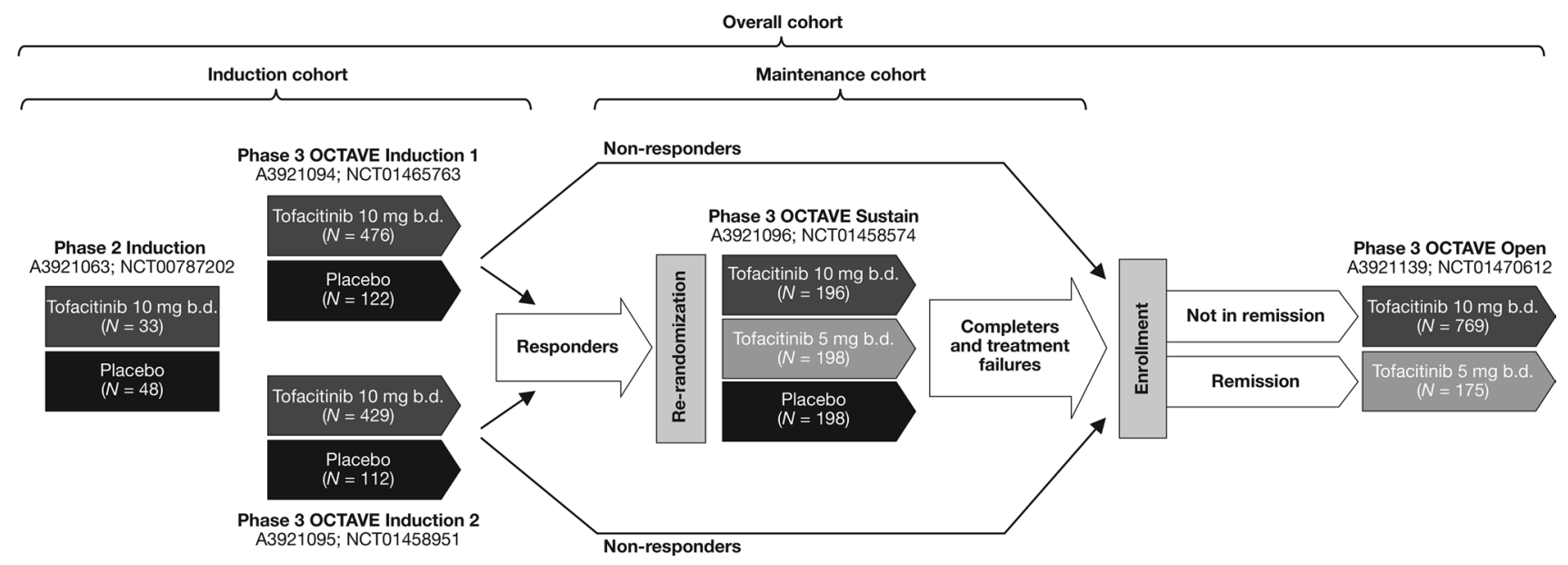

Fig. 1 Overview of the tofacitinib UC clinical studies and cohorts included in this analysis. Clinical response in OCTAVE Induction 1 and 2 was defined as a decrease from induction study baseline total Mayo score of $\geq 3$ points and $\geq 30 \%$, plus a decrease in rectal bleeding subscore of $\geq 1$ point, or an absolute rectal bleeding subscore of
0 or 1. Study A3921139 (OCTAVE Open) is ongoing. Remission was defined as a total Mayo score $\leq 2$ with no individual subscore $>1$, and a rectal bleeding subscore of 0 b.d. twice daily, $N$ number of patients in each treatment group included in the cohort analysis, $U C$ ulcerative colitis 


\section{UC Analysis Cohorts}

The UC analyses included patients who received treatment with placebo, tofacitinib $5 \mathrm{mg}$ twice daily (b.d.), and tofacitinib $10 \mathrm{mg}$ b.d.

Data were analyzed for three UC cohorts. The Induction cohort included patients who received placebo or tofacitinib $10 \mathrm{mg}$ b.d. in phase 2 or phase 3 induction studies. The Maintenance cohort included patients who received placebo, tofacitinib $5 \mathrm{mg}$ b.d., or tofacitinib $10 \mathrm{mg}$ b.d. in OCTAVE Sustain. The Overall cohort included patients who received at least one dose of tofacitinib 5 or $10 \mathrm{mg}$ b.d. in any phase 2 , phase 3, or OLE study (OLE ongoing at the time of analysis; data as of November 2017 data cutoff).

For tofacitinib-treated patients with UC, mean change from induction study baseline CK level over time was evaluated for two phases: the induction phase (patients from the Induction cohort) and the maintenance phase (patients in OCTAVE Sustain who previously received tofacitinib $10 \mathrm{mg}$ b.d. induction therapy).

\section{Rheumatoid Arthritis, Psoriasis, and Psoriatic Arthritis Cohorts}

Data for tofacitinib-treated patients with RA, Pso, and PsA were evaluated for contextualization with the UC cohorts. The RA Overall cohort included tofacitinib-treated patients from phase 1 , phase 2 , phase 3 , phase $3 \mathrm{~b} / 4$, and OLE studies (OLE ORAL Sequel main study was completed; database locked at time of analysis: March 2017) [23-44]. The Pso Overall cohort included tofacitinib-treated patients from phase 2, phase 3, and OLE studies (all of which were completed as of August 2016) [11, 18, 45-48]. The PsA Overall cohort included tofacitinib-treated patients from phase 3 and OLE studies (OLE ongoing at the time of analysis; data as of January 2017) [13, 49, 50]. The RA, Pso, and PsA studies included in these analyses are summarized in Supplementary Table S1.

\section{Creatine Kinase Evaluations and Analyses}

In the UC OCTAVE phase 3 and OLE studies, CK levels were monitored periodically during treatment. CK levels were evaluated in OCTAVE Induction 1 and 2 at baseline and at weeks 2, 4, and 8; in OCTAVE Sustain at baseline and at weeks $4,8,16,24,32,40$, and 52; and in the OLE at baseline and at months 1, 2, 4, 6, 9, and 12. CK values were not routinely monitored in the phase 2 induction study A3921063. Mean changes (and 95\% confidence intervals [CIs]) from induction study baseline CK levels were calculated. In addition, Pearson correlation coefficients for change from baseline $\mathrm{CK}$ levels and C-reactive protein (CRP) were calculated for tofacitinib- and placebo-treated groups at weeks 4 and 8 in the UC Induction cohort, and at weeks 8, 24, and 52 in the UC Maintenance cohort.

In all studies, adverse events (AEs) related to CK elevation were defined as AEs that were reported by the investigator(s) and coded to the Medical Dictionary for Regulatory Activities (MedDRA) preferred term (PT) of "blood creatine phosphokinase increased." The criteria for determining whether an abnormal laboratory test finding should be reported as an $\mathrm{AE}$ were as follows: The test result was associated with accompanying symptoms; or required additional diagnostic testing or medical/surgical intervention; or resulted in a change in study dosing or discontinuation from the study, significant additional concomitant drug treatment, or other therapy; or if the test result was considered to be an $\mathrm{AE}$ by the investigator or sponsor.

Incidence rates (IRs; unique patients with events per 100 patient-years) and 95\% CIs for AEs of CK elevation were calculated using an exact Poisson method. Analysis of IRs excludes data from the phase 2 induction study A3921063 as CK levels were not routinely monitored in that study.

In the OCTAVE studies, any single CK elevation $>3 \times$ the upper limit of normal (ULN) required retesting within $3-5$ days; patients with two sequential CK elevations $>10 \times$ ULN discontinued the study unless the causality was known not to be medically serious (e.g., exercise-induced). ULN for CK was approximately 170 $\mathrm{U} / \mathrm{L}$.

Risk factors for CK elevations $\geq 3 \times \mathrm{ULN}$ and $\geq 5 \times \mathrm{ULN}$ in the UC Overall cohort were evaluated using a Cox regression model. Backward stepwise regression (factors were retained in the final models if significant at the 0.05 level) was used for the evaluation. The following potential factors were included in the initial models: age, predominant dose of tofacitinib received $(5 \mathrm{mg}$ b.d. vs. $10 \mathrm{mg}$ b.d., defined by average total daily dose $<15 \mathrm{mg}$ and $\geq 15 \mathrm{mg}$, respectively), gender, body mass index (BMI), race, baseline CRP, extent of UC, duration of UC, prior TNFi failure, baseline corticosteroid use, prior immunosuppressant use, and geographic region.

All analyses in the UC Induction and Maintenance cohorts were based on the study treatment received. In the UC Overall cohort, analyses were performed based on all patients who received at least one dose of tofacitinib $5 \mathrm{mg}$ b.d. or $10 \mathrm{mg}$ b.d. In the RA, Pso, and PsA Overall cohorts, analyses were performed based on all patients who received at least one dose of tofacitinib. 


\section{Results}

\section{Patients}

Tofacitinib exposure, patient demographics, and CK levels at baseline are presented for the UC, RA, Pso, and PsA cohorts in Table 1.

Tofacitinib exposure was 2051, 22875,8955 , and 1238 patient-years in the UC, RA, Pso, and PsA Overall cohorts, respectively. Median CK at baseline in the UC (63.0 U/L), RA (57.0 U/L), Pso (94.0 U/L), and PsA (87.0 U/L) Overall cohorts was generally similar. Mean age at baseline in the UC cohorts was generally lower than in the RA, Pso, and PsA Overall cohorts. Mean disease duration in the Pso Overall cohort was greater than in the UC cohorts, and in the RA and PsA Overall cohorts. Across the Overall cohorts, the RA cohort had a generally higher proportion of female patients $(82.6 \%)$ than the UC (41.3\%), Pso (30.5\%), and PsA (54.7\%) cohorts.

\section{Changes in CK}

For tofacitinib-treated patients with UC, mean CK increased continually during the 8-week induction phase (Fig. 2). At week 8 , mean change from induction study baseline $\mathrm{CK}$ for patients who received tofacitinib $10 \mathrm{mg}$ b.d. was $91.1 \mathrm{U} / \mathrm{L}$ (95\% CI, 48.1-134.1) versus 19.2 U/L (95\% CI, 8.5-29.9) for patients who received placebo (Fig. 2). Among patients who completed induction treatment with tofacitinib $10 \mathrm{mg}$ b.d., during 52 weeks of further treatment in the OCTAVE Sustain maintenance phase, there were a decrease in mean $\mathrm{CK}$ in patients who were switched to placebo, minimal changes in patients who received tofacitinib $5 \mathrm{mg}$ b.d., and further small increases in patients who continued on tofacitinib $10 \mathrm{mg}$ b.d. (Fig 2). Among patients completing induction with tofacitinib $10 \mathrm{mg}$ b.d. and re-randomized to 52 weeks of maintenance therapy during OCTAVE Sustain, mean change from induction study baseline $\mathrm{CK}$ to the end of the maintenance phase was $35.9 \mathrm{U} / \mathrm{L}$ (95\% CI, 8.1-63.7) with placebo, $90.3 \mathrm{U} / \mathrm{L}$ (95\% CI, 51.9-128.7) with tofacitinib $5 \mathrm{mg}$ b.d., and $115.6 \mathrm{U} / \mathrm{L}$ (95\% CI, 91.6-139.7) with tofacitinib $10 \mathrm{mg}$ b.d. (Fig 2).

Table 1 Demographics and baseline disease characteristics for patients in the tofacitinib UC, RA, Pso, and PsA cohorts

\begin{tabular}{|c|c|c|c|c|c|c|c|c|c|}
\hline & \multicolumn{2}{|c|}{ UC Induction cohort } & \multicolumn{3}{|c|}{ UC Maintenance cohort } & \multirow{2}{*}{$\begin{array}{l}\text { UC Overall } \\
\text { cohort } \\
\text { Tofacitinib } \\
\text { all } N=1157\end{array}$} & \multirow{2}{*}{$\begin{array}{l}\text { RA Overall } \\
\text { cohort } \\
\text { Tofacitinib } \\
\text { all } N=7061\end{array}$} & \multirow{2}{*}{$\begin{array}{l}\text { Pso Overall } \\
\text { cohort } \\
\text { Tofacitinib } \\
\text { all } N=3663\end{array}$} & \multirow{2}{*}{$\begin{array}{l}\text { PsA Overall } \\
\text { cohort } \\
\text { Tofacitinib } \\
\text { all } N=783\end{array}$} \\
\hline & $\begin{array}{l}\text { Placebo } \\
N=282\end{array}$ & $\begin{array}{l}\text { Tofacitinib } \\
10 \text { mg b.d. } \\
N=938\end{array}$ & $\begin{array}{l}\text { Placebo } \\
N=198\end{array}$ & $\begin{array}{l}\text { Tofacitinib } \\
5 \text { mg b.d. } \\
N=198\end{array}$ & $\begin{array}{l}\text { Tofacitinib } \\
10 \text { mg b.d. } \\
N=196\end{array}$ & & & & \\
\hline $\begin{array}{l}\text { Exposure, } \\
\text { patient- } \\
\text { years }\end{array}$ & 44.8 & 156.2 & 100.4 & 146.2 & 154.3 & 2050.5 & 22874.5 & 8954.6 & 1237.9 \\
\hline $\begin{array}{l}\text { Age (years) } \\
\text { mean }(\mathrm{SD})\end{array}$ & $41.4(14.4)$ & $41.3(13.8)$ & $43.4(14.0)$ & $41.9(13.7)$ & $43.0(14.4)$ & $41.3(13.9)$ & $52.1(12.0)$ & $44.8(12.9)$ & $48.7(12.0)$ \\
\hline $\begin{array}{l}\text { Female, } n \\
(\%)\end{array}$ & $127(45.0)$ & $381(40.6)$ & $82(41.4)$ & $95(48.0)$ & $86(43.9)$ & $478(41.3)$ & $5829(82.6)$ & $1117(30.5)$ & $428(54.7)$ \\
\hline $\begin{array}{l}\text { Disease } \\
\text { duration } \\
\text { (years), } \\
\text { mean (SD) }\end{array}$ & $8.2(6.8)$ & $8.2(7.0)$ & $8.8(7.5)$ & $8.3(7.2)$ & $8.7(7.0)$ & $8.2(7.0)$ & $8.0(8.1)$ & $18.3^{\mathrm{a}}(11.9)$ & $7.7(7.2)$ \\
\hline $\begin{array}{l}\text { Median } \\
\text { (range) } \\
\text { CK at } \\
\text { baseline, } \\
\text { U/L }\end{array}$ & $\begin{array}{c}61.0(9.0- \\
591.0)\end{array}$ & $\begin{array}{c}62.0(7.0- \\
3173.0)\end{array}$ & $\begin{array}{c}119.0(7.0- \\
1272.0)\end{array}$ & $\begin{array}{c}124.0(20.0- \\
826.0)\end{array}$ & $\begin{array}{c}117.0(21.0- \\
1948.0)\end{array}$ & $\begin{array}{c}63.0(7.0- \\
3173.0)\end{array}$ & $\begin{array}{c}57.0^{\mathrm{b}}(18.0- \\
1985.0)\end{array}$ & $\begin{array}{l}94.0^{\mathrm{c}} \\
\quad(12.0-21 \\
382.0)\end{array}$ & $\begin{array}{l}87.0^{\mathrm{d}}(18.0- \\
1283.0)\end{array}$ \\
\hline
\end{tabular}

b.d. twice daily, $C K$ creatine kinase, $N$ number of evaluable patients in each treatment group or cohort, $n$ number of patients in the specified category, $P S A$ psoriatic arthritis, $P$ so psoriasis, $R A$ rheumatoid arthritis, $S D$ standard deviation, $U C$ ulcerative colitis

${ }^{\mathrm{a}} N=3660$

${ }^{\mathrm{b}} N=4656$

${ }^{\mathrm{c}} N=3470$

${ }^{\mathrm{d}} N=759$

${ }^{\mathrm{e}}$ For the UC Induction and Overall cohorts, data from the phase 2 induction study (A3921063) are not included as CK was not routinely monitored in this study. UC Induction cohort, $N=234$ for placebo and $N=905$ for tofacitinib $10 \mathrm{mg}$ b.d.; UC Overall cohort, $N=1124$ 

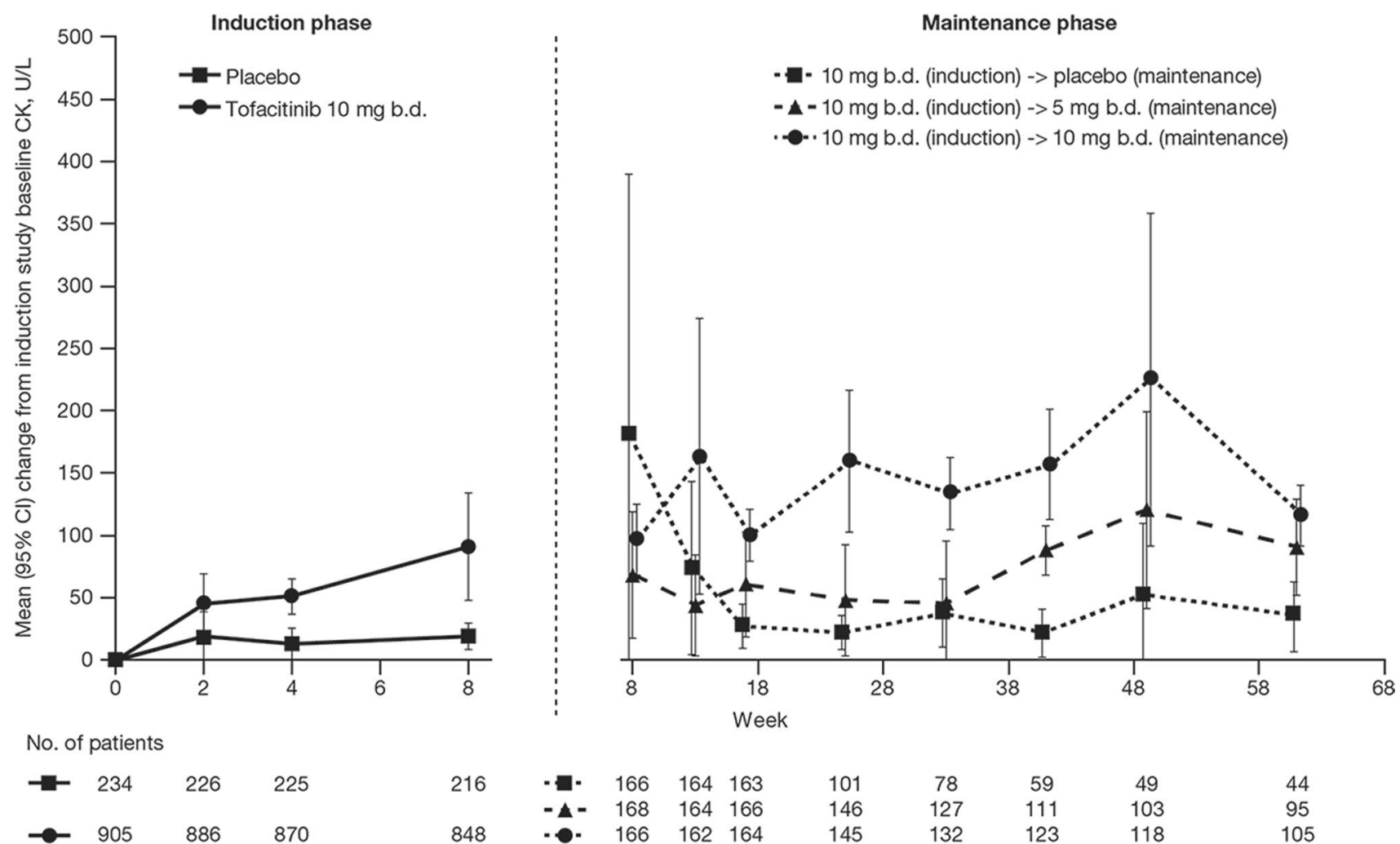

No. of patients

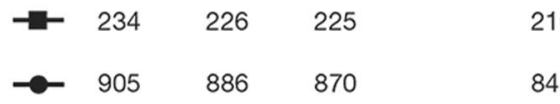

848

Fig. 2 Mean (95\% CI) change from induction study baseline CK during the tofacitinib phase $3 \mathrm{UC}$ induction and maintenance phases. For the induction phase, data from the phase 2 induction study

In the UC Induction and Maintenance cohorts, correlations between change from induction study baseline CK versus change from induction study baseline CRP were weak at all time points evaluated. (Correlation coefficients ranged between 0.0082 and 0.1520 .)

In the RA Overall cohort, mean change from baseline CK was generally stable over the duration of up to 96 months; mean change from baseline CK at month 90 (based on $N=248$ patients with data available at this time point) was 88.3 U/L (95\% CI, 74.6-101.9). In the Pso Overall cohort, mean change from baseline $\mathrm{CK}$ at month $57(N=319$ at this time point) was $125.2 \mathrm{U} / \mathrm{L}$ (95\% CI, 94.1-156.3). In the PsA Overall cohort, mean change from baseline $\mathrm{CK}$ at month 27 ( $N=282$ at this time point) was $84.7 \mathrm{U} / \mathrm{L}(95 \% \mathrm{CI}$, 68.5-100.9) (Fig. 3).

\section{Adverse Events of CK Elevation}

In the UC Induction cohort, AEs of CK elevation (i.e., investigator-determined AEs coded to the MedDRA PT of "blood creatine phosphokinase increased") occurred in $2.8 \%$ of patients receiving tofacitinib $10 \mathrm{mg}$ b.d. $(n / N=25 / 905) \mathrm{com}-$ pared with $0.9 \%$ of placebo-treated patients $(n / N=2 / 234)$ (Table 2).
(A3921063) are not included b.d. twice daily, CI confidence interval, $C K$ creatine kinase, $U C$ ulcerative colitis

IRs for AEs of CK elevation in the UC Maintenance cohort are shown in Fig. 4. The IR for AEs of CK elevation with tofacitinib $10 \mathrm{mg}$ b.d. (8.7 [95\% CI, 4.6-14.8]) was numerically greater than with tofacitinib $5 \mathrm{mg}$ b.d. (4.1 [95\% CI, 1.5-9.0]) or placebo (3.9 [95\% CI, 1.1-10.1]). The IR for AEs of CK elevation with all tofacitinib-treated patients in the UC Overall cohort (6.6 [95\% CI, 5.5-7.9]) was within the range reported with tofacitinib treatment in the Maintenance cohort. IRs for discrete 6-month intervals in the UC Overall cohort are reported in Table 3 and did not increase over time. The IR in the UC Overall cohort was higher than the IR reported in the RA $(2.2[95 \% \mathrm{CI}$, 2.0-2.4]) and PsA (3.7 [95\% CI, 2.7-5.0]) Overall cohorts and similar to that reported in the Pso Overall cohort $(6.5$ [95\% CI, 6.0-7.1]) (Fig. 4).

In the UC Overall cohort, $126(11.2 \%)$ patients reported an $\mathrm{AE}$ of $\mathrm{CK}$ elevation; the majority of cases were mild to moderate in severity (as reported by the investigator), and there were no serious AEs of CK elevation (i.e., events that resulted in death, were life-threatening, resulted in a persistent or significant disability or incapacity, required patient hospitalization or prolongation of existing hospitalization, or resulted in a congenital anomaly or birth defect). No AEs of myopathy were reported in the UC 


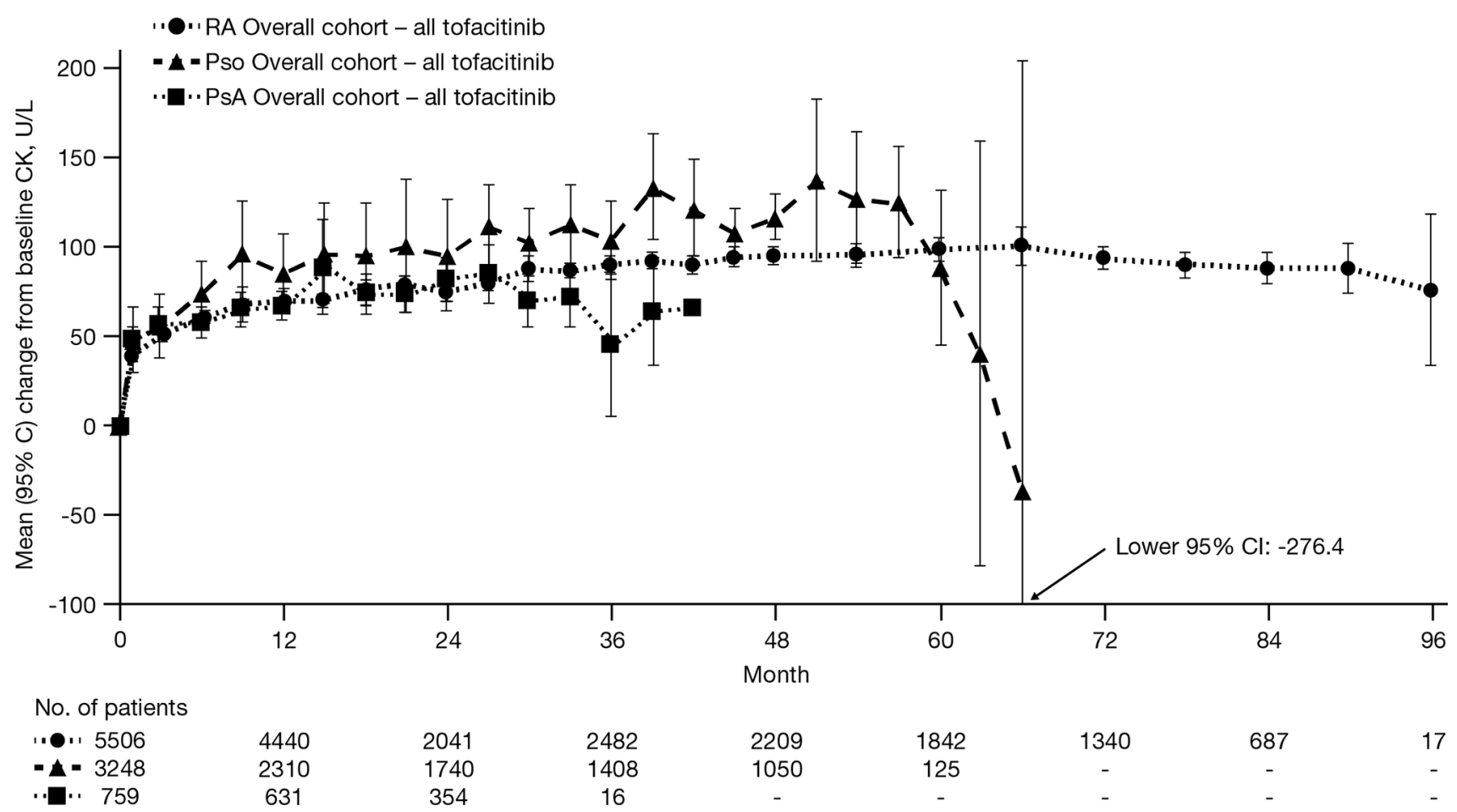

Fig. 3 Mean (95\% CI) change from baseline CK in the RA, Pso, and PsA Overall tofacitinib-treated cohorts. $C I$ confidence interval, $C K$ creatine kinase, $P s A$ psoriatic arthritis, $P$ so psoriasis, $R A$ rheumatoid arthritis

Table 2 Summary of AEs of CK elevation and laboratory parameter abnormalities in the tofacitinib UC, RA, Pso, and PsA cohorts

\begin{tabular}{|c|c|c|c|c|c|c|c|c|c|}
\hline & \multicolumn{2}{|c|}{ UC Induction cohort } & \multicolumn{3}{|c|}{ UC Maintenance cohort } & \multirow{2}{*}{$\begin{array}{l}\text { UC Overall } \\
\text { cohort } \\
\text { Tofaci- } \\
\text { tinib all } \\
N=1124^{\mathrm{a}}\end{array}$} & \multirow{2}{*}{$\begin{array}{l}\text { RA Overall } \\
\text { cohort } \\
\text { Tofaci- } \\
\text { tinib all } \\
N=7061\end{array}$} & \multirow{2}{*}{$\begin{array}{l}\text { Pso Overall } \\
\text { cohort } \\
\text { Tofaci- } \\
\text { tinib all } \\
N=3663\end{array}$} & \multirow{2}{*}{$\begin{array}{l}\text { PsA Overall } \\
\text { cohort } \\
\text { Tofacitinib } \\
\text { all } N=783\end{array}$} \\
\hline & $\begin{array}{l}\text { Placebo } \\
N=234^{\mathrm{a}}\end{array}$ & $\begin{array}{l}\text { Tofacitinib } \\
10 \text { mg b.d. } \\
N=905^{\mathrm{a}}\end{array}$ & $\begin{array}{l}\text { Placebo } \\
N=198\end{array}$ & $\begin{array}{l}\text { Tofacitinib } \\
5 \text { mg b.d. } \\
N=198\end{array}$ & $\begin{array}{l}\text { Tofacitinib } \\
10 \text { mg b.d. } \\
N=196\end{array}$ & & & & \\
\hline \multicolumn{10}{|l|}{ AE of CK elevation } \\
\hline$n(\%)$ & $3(1.3)$ & $25(2.8)$ & $4(2.0)$ & $6(3.0)$ & $13(6.6)$ & $126(11.2)$ & $495(7.0)$ & $529(14.4)$ & $45(5.7)$ \\
\hline $\begin{array}{l}\text { Number leading to } \\
\text { discontinuation } \\
\text { from the study, } \\
n(\%)\end{array}$ & $1(33.3)$ & $0(0.0)$ & $1(25.0)$ & $0(0.0)$ & $1(7.7)$ & $2(1.6)$ & $24(4.8)$ & $29(5.5)$ & $0(0.0)$ \\
\hline \multicolumn{10}{|l|}{$\begin{array}{l}\text { CK laboratory } \\
\text { parameter abnor- } \\
\text { malities }\end{array}$} \\
\hline $\begin{array}{l}\text { Any single CK eleva- } \\
\text { tion }>3 \times \mathrm{ULN},{ }^{\mathrm{b}} \\
n(\%)\end{array}$ & $7(3.0)$ & $39(4.3)$ & $10(5.1)$ & $15(7.6)$ & $26(13.3)$ & $210(18.7)$ & $662(9.4)$ & $864(23.6)$ & $89(11.4)$ \\
\hline $\begin{array}{l}\text { Two sequential } \\
\text { CK eleva- } \\
\text { tions }>10 \times \mathrm{ULN},^{\mathrm{b}} \\
n(\%)\end{array}$ & $0(0.0)$ & $1(0.1)$ & $0(0.0)$ & $0(0.0)$ & $2(1.0)$ & $9(0.8)$ & $6(0.1)$ & $11(0.3)$ & $1(0.1)$ \\
\hline
\end{tabular}

AEs of CK elevation were investigator-determined AEs coded to the MedDRA PT of "blood creatine phosphokinase increased"

$A E$ adverse event, b.d. twice daily, $C K$ creatine kinase, $N$ number of evaluable patients in each treatment group or cohort, $n$ number of patients with response in the specified category, MedDRA Medical Dictionary for Regulatory Activities, PsA psoriatic arthritis, Pso psoriasis, PT preferred term, $R A$ rheumatoid arthritis, $U C$ ulcerative colitis, $U L N$ upper limit of normal

${ }^{a}$ For the UC Induction and Overall cohorts, data from the phase 2 induction study (A3921063) are not included as CK elevation was not routinely monitored in this study

${ }^{\mathrm{b}} \mathrm{ULN}$ was approximately $170 \mathrm{U} / \mathrm{L}$ 
Fig. 4 IRs (95\% CI) for AEs of CK elevation in the UC Maintenance and Overall cohorts, and the RA, Pso, and PsA Overall cohorts. IRs for AEs of CK elevation in the UC Induction cohort are not shown due to the short duration (8 weeks) of the UC induction studies. For the UC Overall cohort, data from the phase 2 induction study (A3921063) are not included. $A E$ adverse event, b.d. twice daily, $C I$ confidence interval, $C K$ creatine kinase, $I R$ incidence rate, $N$ number of evaluable patients in each treatment group or cohort, $n$ number of unique patients with events, $P s A$ psoriatic arthritis, Pso psoriasis, $R A$ rheumatoid arthritis, $U C$ ulcerative colitis

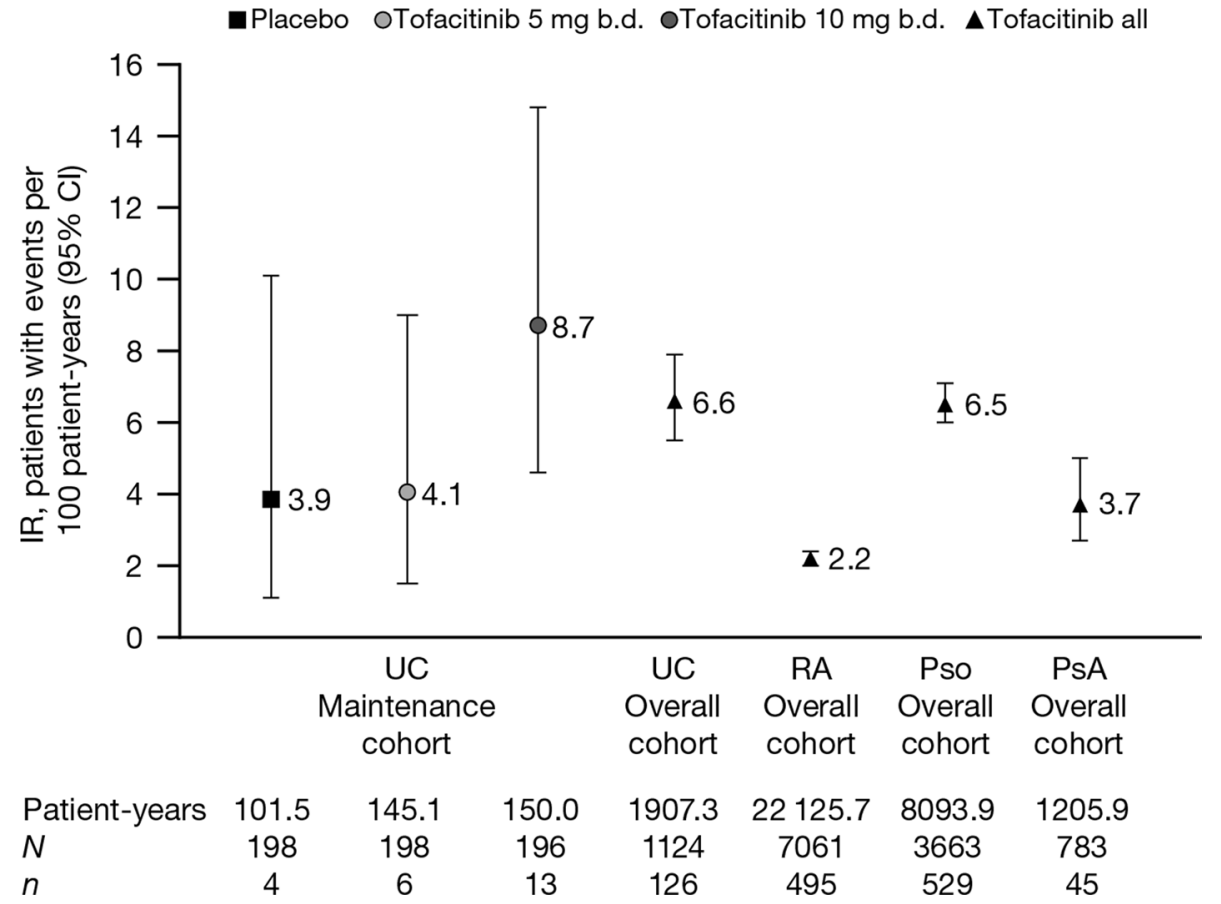

Table 3 IRs for AEs of CK elevation in the UC Overall cohort by 6-month interval

\begin{tabular}{|c|c|c|c|c|c|c|}
\hline & \multicolumn{6}{|c|}{ UC Overall cohort-Tofacitinib all } \\
\hline & $0-6$ months $N=1124$ & $\begin{array}{l}>6- \\
12 \text { months } N=737\end{array}$ & $\begin{array}{l}>12- \\
18 \text { months } N=622\end{array}$ & $\begin{array}{l}>18- \\
24 \text { months } N=540\end{array}$ & $\begin{array}{l}>24- \\
30 \text { months } N=481\end{array}$ & $>30$ months $N=395$ \\
\hline $\begin{array}{l}\text { Exposure, } \\
\text { patient- } \\
\text { years }\end{array}$ & 475.4 & 335.0 & 289.3 & 254.2 & 223.3 & 330.1 \\
\hline $\begin{array}{l}\text { Number of } \\
\text { patients } \\
\text { with AEs } \\
\text { of CK } \\
\text { elevation, } \\
n(\%)\end{array}$ & $62(5.5)$ & $17(2.3)$ & $13(2.1)$ & $9(1.7)$ & $11(2.3)$ & $14(3.5)$ \\
\hline IR $(95 \%$ CI) & $13.0(10.0-16.7)$ & $5.1(3.0-8.1)$ & $4.5(2.4-7.7)$ & $3.5(1.6-6.7)$ & $4.9(2.5-8.8)$ & $4.2(2.3-7.1)$ \\
\hline
\end{tabular}

Data from the phase 2 induction study (A3921063) are not included

$A E$ adverse event, $C I$ confidence interval, $C K$ creatine kinase, $I R$ incidence rate, $N$ number of patients evaluable in the specified time period, $n$ number of unique patients with events, $U C$ ulcerative colitis

program. One $(0.1 \%)$ patient in the UC Overall cohort had an $\mathrm{AE}$ of myositis.

In the UC Overall cohort, for the $126(11.2 \%)$ patients who reported an $\mathrm{AE}$ of $\mathrm{CK}$ elevation, the median time to event was 183 days (range 1-1579 days). In the RA Overall cohort, 495 (7.0\%) patients had AEs of CK elevation, with a median time to event of 505 days (range 1-2873 days). In the Pso Overall cohort, 529 (14.4\%) patients had AEs of CK elevation, with a median time to event of 266 days (range 1-1707 days). In the PsA Overall cohort, 45 (5.7\%) patients with AEs of CK elevation, with a median time to event of 169 days (range 15-696 days).

In the tofacitinib UC clinical studies, one patient who received placebo during OCTAVE Sustain developed rhabdomyolysis on day 224 of the study. The patient had received 63 days of tofacitinib $10 \mathrm{mg}$ b.d. in OCTAVE Induction 1 and was then re-randomized to receive placebo in OCTAVE Sustain. The AE of rhabdomyolysis was mild in severity, did not require drug discontinuation, and resolved on day 250 of OCTAVE Sustain. The patient had CK and serum creatinine 
within normal range at baseline of OCTAVE Induction 1 . On day 56 of OCTAVE Induction 1 (during treatment with tofacitinib $10 \mathrm{mg}$ b.d.), $\mathrm{CK}$ was $312 \mathrm{U} / \mathrm{L}$ and serum creatinine was within normal range. In OCTAVE Sustain (in which the patient was re-randomized to receive placebo), CK decreased to $103 \mathrm{U} / \mathrm{L}$ on day 56 of OCTAVE Sustain and was $248 \mathrm{U} / \mathrm{L}$ on day 224. Serum creatinine reached a peak value of $1.5 \mathrm{mg} / \mathrm{dL}$ on day 224. Given the marginal increase in CK and serum creatinine at the time of the event, the event did not meet the conventional definition of rhabdomyolysis [51]. The elapsed time between the last dose of tofacitinib and onset of the AE suggested this was unlikely to be related to tofacitinib treatment.

AEs of CK elevation that required discontinuation from the study occurred infrequently in the UC program; in the Overall cohort, two of the 126 patients $(1.6 \%$; both of whom were receiving tofacitinib $10 \mathrm{mg}$ b.d. at the time of the event) were required to discontinue.

\section{CK Laboratory Parameter Abnormalities}

In the UC Induction and Maintenance cohorts, the proportion of patients meeting criteria for monitoring (any single CK elevation $>3 \times \mathrm{ULN}$ ) was numerically higher with tofacitinib treatment versus placebo (Table 2). The proportion of patients meeting criteria for monitoring in the UC Overall cohort (18.7\%) was greater than reported in the RA $(9.4 \%)$ and PsA (11.4\%) Overall cohorts and lower than reported in the Pso (23.6\%) Overall cohort. The observed differences in age and gender across the disease cohorts in this analysis are potential confounders for these observations. The proportion of patients with two sequential CK elevations $>10 \times \mathrm{ULN}$ was $\leq 1.0 \%$ across each of the UC, RA, Pso, and PsA cohorts in this analysis.

\section{Risk Factor Analysis for CK Laboratory Parameter Abnormalities in the UC Overall Cohort}

Results of the multivariate Cox regression risk factor analyses for CK elevations $\geq 3 \times \mathrm{ULN}$ and $\geq 5 \times \mathrm{ULN}$ in the UC Overall cohort are summarized in Supplementary Table S2. Gender, age at onset, and geographic region were retained in the final model for CK elevations $\geq 3 \times \mathrm{ULN}$ and $\geq 5 \times \mathrm{ULN}$. Additionally, race was also retained in the final model for CK elevations $\geq 3 \times$ ULN (see Supplementary Table S2). Tofacitinib dose was evaluated but was not identified as a significant risk factor for CK elevations $\geq 3 \times U L N$ and $\geq 5 \times U L N$ in the final models.

\section{Discussion}

In this analysis of data from tofacitinib UC clinical studies, tofacitinib treatment in patients with moderately to severely active UC appeared to be associated with reversible CK elevations. Increases in CK began within the first two weeks of tofacitinib induction therapy and continued to week 8 of induction treatment. Continued therapy with tofacitinib beyond week 8 did not result in further clinically meaningful elevations in CK. Elevations in CK were not associated with clinically significant AEs such as rhabdomyolysis or myopathy. Few AEs of CK elevation required patients to discontinue participation in these studies. Multivariate Cox risk factor analysis identified male gender and younger age as significant risk factors for CK elevations $\geq 3 \times U L N$ and $\geq 5 \times U L N$. Results in the tofacitinib UC program were generally consistent with observations in the tofacitinib RA, Pso, and PsA clinical development programs. Elucidation of the mechanism for the observed changes in $\mathrm{CK}$ requires further investigation.

Results of this integrated analysis are also consistent with previous analyses from the tofacitinib rheumatology and dermatology clinical development programs that specifically evaluated the effects of tofacitinib on CK levels $[18,19]$. Analyses in patients with Pso demonstrated that increases in CK were readily reversible in patients who had their tofacitinib therapy withdrawn, and the degree of elevation itself was not clinically significant [18]. In patients with RA, the effect of tofacitinib on muscle biomarkers, including CK, was evaluated. In this analysis, mean CK levels plateaued following six months of tofacitinib treatment, remained within the normal reference range, and were not associated with clinical myopathy [19].

Our findings are also consistent with data for other therapies with an immunosuppressant mode of action used to treat inflammatory diseases, including the JAK inhibitors baricitinib [14], upadacitinib [15-17], and TNFi infliximab [20]. In RA clinical studies of baricitinib [14], dose-dependent increases in CK were observed within one week, which plateaued at 8-12 weeks. Median CK increase from baseline with the highest baricitinib dose (4 mg once daily) was $52 \mathrm{U} / \mathrm{L}$ at week 16 . AEs related to muscle injury were infrequent, and no rhabdomyolysis associated with baricitinib was observed [14]. Elevated CK levels were among the most common AEs reported in clinical trials of upadacitinib in UC [15], ankylosing spondylitis [16], and RA [17]. In a registry study of infliximab-treated patients with IBD, $30.5 \%$ had elevated CK levels (absolute CK > 180 U/L), but none reported persistent symptoms potentially related to myopathy [20]. Other commonly used medications associated with increases in CK include antipsychotics and certain beta blockers [2], 
as well as statins, where CK elevations $2-10 \times \mathrm{ULN}$ occur in around $5 \%$ of users [4]. As prescription drugs are a common cause of CK elevation, it is recommended that affected patients are monitored, and their medications reviewed [4]. For patients with elevated CK levels with no apparent medical explanation, current guidelines recommend that a muscle biopsy be performed for further investigation if one or more of the following are present: CK elevation $\geq 3 \times$ ULN, myopathic electromyogram, or if the patient is $<25$ years of age [2].

In the findings of the Cox risk factor analysis performed in the present study, male gender and younger age were associated with increased risk for elevated CK levels, which is consistent with previously reported observations of higher CK activity among men compared with women $[2,5,6,8-10]$ and among younger subjects (particularly young adult males, where the difference may be driven by higher muscle mass in this group) versus older subjects [7]. Tofacitinib dose was not identified as a significant risk factor in this analysis.

Although the profile of CK elevations and AEs was generally similar across the different disease populations analyzed, comparisons among populations should be interpreted with caution due to differences in patient population characteristics. In addition, differences in the age and gender makeup of the patient populations - the mean age of the UC Overall cohort (41.3 years) was numerically lower than the RA (52.1), Pso (44.8), and PsA (48.7) Overall cohorts, and $83 \%$ of patients in the RA Overall cohort were female compared with $41 \%, 31 \%$, and $55 \%$ in the UC, Pso, and PsA Overall cohorts-are of particular relevance, given the previously reported variation in the normal range of CK levels by age and gender $[6,8]$.

Advantages of this analysis include the large numbers of tofacitinib-treated patients enrolled across multiple disease populations, and the long duration of follow-up ( $>22$ 000 patient-years in the RA Overall cohort). In addition, detailed data on CK and associated AEs were collected in each of the UC, RA, Pso, and PsA clinical trial programs. However, the approach of pooling potentially heterogeneous patient populations for analysis in the Overall cohorts is a potential limitation of this study, as patients' prior treatment history and permitted concomitant medications were different in some of the trials pooled in the Overall cohorts. A further limitation is that some information relating to AEs of CK elevation was dependent upon interpretation and reporting by site investigators, and this may not have been reported in a uniform fashion.

In conclusion, these analyses of clinical trial data from patients with UC, RA, Pso, and PsA demonstrated that although CK elevations in tofacitinib-treated patients were a relatively common occurrence, they were minor, were reversible, and were not associated with clinically important signs or symptoms.

Acknowledgments The authors would like to thank the patients, investigators, and trial teams who were involved in the tofacitinib clinical trial programs. Medical writing support, under the guidance of the authors, was provided by Daniel Binks, PhD, CMC Connect, McCann Health Medical Communications, and was funded by Pfizer Inc, New York, NY, USA, in accordance with Good Publication Practice (GPP3) guidelines (Ann Intern Med. 2015;163:461-464). John D. Isaacs is supported by the NIHR Newcastle Biomedical Research Centre (BRC). The views expressed are those of the author(s) and not necessarily those of the NIHR or the Department of Health and Social Care.

Author's contribution RP, JDI, LAC, WW, AM, KK, LW, GC, and CS were involved in the conception and design of the study/analyses, data interpretation, and manuscript drafting, reviewing, and development. RP (UC studies) and JDI (RA studies) were involved in the recruitment of study patients. All authors read and approved the manuscript.

Funding These studies were sponsored by Pfizer Inc. Medical writing support was funded by Pfizer Inc.

Availability of data and materials Upon request, and subject to certain criteria, conditions, and exceptions (see https://www.pfizer.com/scien ce/clinical-trials/trial-data-and-results for more information), Pfizer will provide access to individual de-identified participant data from Pfizer-sponsored global interventional clinical studies conducted for medicines, vaccines, and medical devices (1) for indications that have been approved in the USA and/or EU or (2) in programs that have been terminated (i.e., development for all indications has been discontinued). Pfizer will also consider requests for the protocol, data dictionary, and statistical analysis plan. Data may be requested from Pfizer trials 24 months after study completion. The de-identified participant data will be made available to researchers whose proposals meet the research criteria and other conditions, and for which an exception does not apply, via a secure portal. To gain access, data requestors must enter into a data access agreement with Pfizer.

\section{Compliance with Ethical Standards}

Conflict of interest RP has received consulting fees from AbbVie, Amgen, Aptalis, AstraZeneca, Baxter, Biogen, Bristol-Myers Squibb, Celgene, Centocor, Cubist, Eisai, Elan, Ferring, Gilead, GlaxoSmithKline, Janssen, Merck, Pfizer Inc, Robarts Clinical Trials, Salix, Samsung Bioepis, Shire, Takeda, and UCB; has received research Grants from AbbVie, Ferring, Janssen, and Takeda; has received lectures and/ or speaker bureau fees from AbbVie, Aptalis, AstraZeneca, Ferring, Janssen, Merck, Prometheus, Shire, and Takeda; and has received advisory board fees from Abbott, AbbVie, Amgen, Aptalis, AstraZeneca, Baxter, Bristol-Myers Squibb, Celgene, Centocor, Cubist, Eisai, Elan, Ferring, Genentech, GlaxoSmithKline, Janssen, Merck, Pfizer Inc, Salix, Schering-Plough, Shire, Takeda, and UCB. JDI has been a consultant for, and/or has received research Grants or speaker fees from, AbbVie, Amgen, Eli Lilly, Gilead, Merck, Pfizer Inc, Roche, and UCB. LAC has served as a consultant for Pfizer Inc; has received research Grants from BioRad, Pfizer Inc, and PredictImmune; and has received advisory board fees from Gilead and Janssen. WW, AM, KK, LW, GC, and CS are employees and stockholders of Pfizer Inc.

Conference presentation These data were presented at the 2018 Annual Scientific Meeting of the American College of Gastroenterology, Philadelphia, PA, USA, October 5-10, 2018. 
Ethical approval All studies received appropriate Institutional Review Board and/or Independent Ethics Committee approval. All patients provided written informed consent.

Informed consent Informed consent was obtained from all individual participants included in the study.

Open Access This article is licensed under a Creative Commons Attribution-NonCommercial 4.0 International License, which permits any non-commercial use, sharing, adaptation, distribution and reproduction in any medium or format, as long as you give appropriate credit to the original author(s) and the source, provide a link to the Creative Commons licence, and indicate if changes were made. The images or other third party material in this article are included in the article's Creative Commons licence, unless indicated otherwise in a credit line to the material. If material is not included in the article's Creative Commons licence and your intended use is not permitted by statutory regulation or exceeds the permitted use, you will need to obtain permission directly from the copyright holder. To view a copy of this licence, visit http://creativecommons.org/licenses/by-nc/4.0/.

\section{References}

1. Kitzenberg D, Colgan SP, Glover LE. Creatine kinase in ischemic and inflammatory disorders. Clin Transl Med. 2016;5:31.

2. Kyriakides T, Angelini C, Schaefer J, et al. EFNS guidelines on the diagnostic approach to pauci- or asymptomatic hyperCKemia. Eur J Neurol. 2010;17:767-773.

3. Bagley WH, Yang H, Shah KH. Rhabdomyolysis. Intern Emerg Med. 2007;2:210-218.

4. Moghadam-Kia S, Oddis CV, Aggarwal R. Approach to asymptomatic creatine kinase elevation. Cleve Clin J Med. 2016;83:37-42.

5. Wong ET, Cobb C, Umehara MK, et al. Heterogeneity of serum creatine kinase activity among racial and gender groups of the population. Am J Clin Pathol. 1983;79:582-586.

6. Neal RC, Ferdinand KC, Ycas J, Miller E. Relationship of ethnic origin, gender, and age to blood creatine kinase levels. Am J Med. 2009;122:73-78.

7. Brancaccio P, Maffulli N, Limongelli FM. Creatine kinase monitoring in sport medicine. Br Med Bull. 2007;81-82:209-230.

8. Lev EI, Tur-Kaspa I, Ashkenazy I, et al. Distribution of serum creatine kinase activity in young healthy persons. Clin Chim Acta. 1999;279:107-115.

9. Lilleng H, Abeler K, Johnsen SH, et al. Variation of serum creatine kinase (CK) levels and prevalence of persistent hyperCKemia in a Norwegian normal population. The Troms $\varnothing$ study. Neuromuscul Disord. 2011;21:494-500.

10. Brewster LM, Mairuhu G, Sturk A, van Montfrans GA. Distribution of creatine kinase in the general population: implications for statin therapy. Am Heart J. 2007;154:655-661.

11. Papp KA, Krueger JG, Feldman SR, et al. Tofacitinib, an oral Janus kinase inhibitor, for the treatment of chronic plaque psoriasis: long-term efficacy and safety results from 2 randomized phase-III studies and 1 open-label long-term extension study. $J$ Am Acad Dermatol. 2016;74:841-850.

12. Sandborn WJ, Su C, Sands BE, et al. Tofacitinib as induction and maintenance therapy for ulcerative colitis. $N$ Engl J Med. 2017:376:1723-1736.

13. Gladman D, Rigby W, Azevedo VF, et al. Tofacitinib for psoriatic arthritis in patients with an inadequate response to TNF inhibitors. N Engl J Med. 2017;377:1525-1536.
14. US Food and Drug Administration. OLUMIANT (baricitinib): Highlights of Prescribing Information. 2018. Available at: https:// www.accessdata.fda.gov/drugsatfda_docs/label/2018/207924s000 lbl.pdf. Accessed June 5, 2019.

15. Sandborn WJ, Ghosh S, Panes J, et al. Efficacy of upadacitinib in a randomized trial of patients with active ulcerative colitis. Gastroenterology. 2020;158:2139-2149.

16. van der Heijde D, Song IH, Pangan AL, et al. Efficacy and safety of upadacitinib in patients with active ankylosing spondylitis (SELECT-AXIS 1): a multicentre, randomised, double-blind, placebo-controlled, phase 2/3 trial. Lancet. 2019;394:2108-2117.

17. Fleischmann R, Pangan AL, Song IH, et al. Upadacitinib versus placebo or adalimumab in patients with rheumatoid arthritis and an inadequate response to methotrexate: results of a phase III, double-blind, randomized controlled trial. Arthritis Rheumatol. 2019;71:1788-1800.

18. Bissonnette R, Iversen L, Sofen $\mathrm{H}$, et al. Tofacitinib withdrawal and retreatment in moderate-to-severe chronic plaque psoriasis: a randomized controlled trial. Br J Dermatol. 2015;172:1395-1406.

19. Isaacs JD, Zuckerman A, Krishnaswami S, et al. Changes in serum creatinine in patients with active rheumatoid arthritis treated with tofacitinib: results from clinical trials. Arthritis Res Ther. 2014; 16:R158.

20. Theodoraki E, Orfanoudaki E, Foteinogiannopoulou K, Koutroubakis IE. Asymptomatic hyperCKemia during infliximab therapy in patients with inflammatory bowel disease. Inflamm Bowel Dis. 2018;24:1266-1271.

21. Ordás I, Feagan BG, Sandborn WJ. Therapeutic drug monitoring of tumor necrosis factor antagonists in inflammatory bowel disease. Clin Gastroenterol Hepatol. 2012;10:1079-1087.

22. Lichtenstein GR, Loftus EV Jr, Bloom S, et al. Tofacitinib, an oral Janus kinase inhibitor, in the treatment of ulcerative colitis: an interim analysis of an open-label, long-term extension study with up to 49 years of treatment [abstract]. Am J Gastroenterol. 2018;113:5329.

23. Charles-Schoeman C, Fleischmann R, Davignon J, et al. Potential mechanisms leading to the abnormal lipid profile in patients with rheumatoid arthritis versus healthy volunteers and reversal by tofacitinib. Arthritis Rheumatol. 2015;67:616-625.

24. Kremer JM, Kivitz AJ, Simon-Campos JA, et al. Evaluation of the effect of tofacitinib on measured glomerular filtration rate in patients with active rheumatoid arthritis: results from a randomised controlled trial. Arthritis Res Ther. 2015;17:95.

25. Kremer JM, Bloom BJ, Breedveld FC, et al. The safety and efficacy of a JAK inhibitor in patients with active rheumatoid arthritis: results of a double-blind, placebo-controlled phase IIa trial of three dosage levels of CP-690,550 versus placebo. Arthritis Rheum. 2009;60:1895-1905.

26. Kremer JM, Cohen S, Wilkinson BE, et al. A phase IIb dose-ranging study of the oral JAK inhibitor tofacitinib (CP-690,550) versus placebo in combination with background methotrexate in patients with active rheumatoid arthritis and an inadequate response to methotrexate alone. Arthritis Rheum. 2012;64:970-981.

27. Fleischmann R, Cutolo M, Genovese MC, et al. Phase IIb doseranging study of the oral JAK inhibitor tofacitinib (CP-690,550) or adalimumab monotherapy versus placebo in patients with active rheumatoid arthritis with an inadequate response to disease-modifying antirheumatic drugs. Arthritis Rheum. 2012;64:617-629.

28. Tanaka Y, Suzuki M, Nakamura H, Toyoizumi S, Zwillich SH, Tofacitinib Study Investigators. Phase II study of tofacitinib (CP$690,550)$ combined with methotrexate in patients with rheumatoid arthritis and an inadequate response to methotrexate. Arthritis Care Res Hoboken. 2011;63:1150-1158.

29. Tanaka Y, Takeuchi T, Yamanaka H, Nakamura H, Toyoizumi S, Zwillich S. Efficacy and safety of tofacitinib as monotherapy 
in Japanese patients with active rheumatoid arthritis: a 12-week, randomized, phase 2 study. Mod Rheumatol. 2015;25:514-521.

30. McInnes IB, Kim HY, Lee SH, et al. Open-label tofacitinib and double-blind atorvastatin in rheumatoid arthritis patients: a randomised study. Ann Rheum Dis. 2014;73:124-131.

31. Conaghan PG, Østergaard M, Bowes MA, et al. Comparing the effects of tofacitinib, methotrexate and the combination, on bone marrow oedema, synovitis and bone erosion in methotrexatenaive, early active rheumatoid arthritis: results of an exploratory randomised MRI study incorporating semiquantitative and quantitative techniques. Ann Rheum Dis. 2016;75:1024-1033.

32. Boyle DL, Soma K, Hodge J, et al. The JAK inhibitor tofacitinib suppresses synovial JAK1-STAT signalling in rheumatoid arthritis. Ann Rheum Dis. 2015;74:1311-1316.

33. Winthrop KL, Silverfield J, Racewicz A, et al. The effect of tofacitinib on pneumococcal and influenza vaccine responses in rheumatoid arthritis. Ann Rheum Dis. 2016;75:687-695.

34. Winthrop KL, Wouters AG, Choy EH, et al. The safety and immunogenicity of live zoster vaccination in patients with rheumatoid arthritis before starting tofacitinib: a randomized phase II trial. Arthritis Rheumatol. 2017;69:1969-1977.

35. Burmester GR, Blanco R, Charles-Schoeman C, et al. Tofacitinib (CP-690,550) in combination with methotrexate in patients with active rheumatoid arthritis with an inadequate response to tumour necrosis factor inhibitors: a randomised phase 3 trial. Lancet. 2013;381:451-460.

36. van der Heijde D, Tanaka Y, Fleischmann R, et al. Tofacitinib (CP-690,550) in patients with rheumatoid arthritis receiving methotrexate: twelve-month data from a twenty-four-month phase III randomized radiographic study. Arthritis Rheum. 2013;65:559-570.

37. Fleischmann R, Kremer J, Cush J, et al. Placebo-controlled trial of tofacitinib monotherapy in rheumatoid arthritis. N Engl J Med. 2012;367:495-507.

38. Kremer J, Li Z-G, Hall S, et al. Tofacitinib in combination with nonbiologic disease-modifying antirheumatic drugs in patients with active rheumatoid arthritis: a randomized trial. Ann Intern Med. 2013;159:253-261.

39. van Vollenhoven RF, Fleischmann R, Cohen $\mathrm{S}$, et al. Tofacitinib or adalimumab versus placebo in rheumatoid arthritis. $N$ Engl $J$ Med. 2012;367:508-519.

40. Lee EB, Fleischmann R, Hall S, et al. Tofacitinib versus methotrexate in rheumatoid arthritis. N Engl J Med. 2014;370:2377-2386.

41. Fleischmann R, Mysler E, Hall S, et al. Efficacy and safety of tofacitinib monotherapy, tofacitinib with methotrexate, and adalimumab with methotrexate in patients with rheumatoid arthritis (ORAL strategy): a phase $3 \mathrm{~b} / 4$, double-blind, head-to-head, randomised controlled trial. Lancet. 2017;390:457-468.

42. Wollenhaupt J, Silverfield J, Lee EB, et al. Safety and efficacy of tofacitinib, an oral Janus kinase inhibitor, for the treatment of rheumatoid arthritis in open-label, longterm extension studies. $J$ Rheumatol. 2014;41:837-852.

43. Yamanaka H, Tanaka Y, Takeuchi T, et al. Tofacitinib, an oral Janus kinase inhibitor, as monotherapy or with background methotrexate, in Japanese patients with rheumatoid arthritis: an openlabel, long-term extension study. Arthritis Res Ther. 2016;18:34.

44. Wollenhaupt J, Silverfield J, Lee EB, et al. Tofacitinib, an oral Janus kinase inhibitor, in the treatment of rheumatoid arthritis: safety and efficacy in open-label, long-term extension studies over 9 years [abstract]. Arthritis Rheumatol. 2017;69:683-684.

45. Krueger J, Clark JD, Suárez-Fariñas M, et al. Tofacitinib attenuates pathologic immune pathways in patients with psoriasis: a randomized phase 2 study. J Allergy Clin Immunol. 2016;137:1079-1090.

46. Papp KA, Menter A, Strober B, et al. Efficacy and safety of tofacitinib, an oral Janus kinase inhibitor, in the treatment of psoriasis: a phase $2 \mathrm{~b}$ randomized placebo-controlled dose-ranging study. $\mathrm{Br}$ J Dermatol. 2012;167:668-677.

47. Papp KA, Menter MA, Abe M, et al. Tofacitinib, an oral Janus kinase inhibitor, for the treatment of chronic plaque psoriasis: results from two, randomized, placebo-controlled, phase III trials. Br J Dermatol. 2015;173:949-961.

48. Bachelez H, van de Kerkhof PC, Strohal R, et al. Tofacitinib versus etanercept or placebo in moderate-to-severe chronic plaque psoriasis: a phase 3 randomised non-inferiority trial. Lancet. 2015;386:552-561.

49. Mease P, Hall S, FitzGerald O, et al. Tofacitinib or adalimumab versus placebo for psoriatic arthritis. $N$ Engl J Med. 2017;377:1537-1550.

50. Nash P, Coates LC, Kivitz AJ, et al. Safety and efficacy of tofacitinib, an oral Janus kinase inhibitor, up to 24 months in patients with active psoriatic arthritis: interim data from OPAL balance, an open-label, long-term extension study [abstract]. Ann Rheum Dis. 2017;76:682.

51. Chavez LO, Leon M, Einav S, Varon J. Beyond muscle destruction: a systematic review of rhabdomyolysis for clinical practice. Crit Care. 2016;20:135.

Publisher's Note Springer Nature remains neutral with regard to jurisdictional claims in published maps and institutional affiliations.

\section{Affiliations}

\section{Remo Panaccione ${ }^{1}\left[\right.$ ] John D. Isaacs ${ }^{2} \cdot$ Lea Ann Chen $^{3} \cdot$ Wenjin Wang $^{4} \cdot$ Amy Marren $^{4} \cdot$ Kenneth Kwok $^{5} \cdot$ Lisy Wang $^{6}$. Gary Chan ${ }^{4}$. Chinyu Su ${ }^{4}$}

John D. Isaacs

john.isaacs@ncl.ac.uk

Lea Ann Chen

Lea.Chen@nyumc.org

Wenjin Wang

wenjin.wang@pfizer.com

Amy Marren

Amy.Marren@pfizer.com

Kenneth Kwok

kenneth.kwok@pfizer.com
Lisy Wang

Lisy.Wang@pfizer.com

Gary Chan

gary.chan@pfizer.com

Chinyu Su

chinyu.su@pfizer.com

1 Department of Medicine, University of Calgary, 3330

Hospital Drive NW, Calgary, AB T2N 4N1, Canada 
2 Translational and Clinical Research Institute, Newcastle University and Musculoskeletal Unit, Newcastle upon Tyne Hospitals NHS Foundation Trust, Newcastle upon Tyne, UK

3 New York University School of Medicine, New York, NY, USA

4 Inflammation and Immunology, Pfizer Inc, Collegeville, PA, USA
5 Inflammation and Immunology, Pfizer Inc, New York, NY, USA

6 Inflammation and Immunology, Pfizer Inc, Groton, CT, USA 